\title{
COMMENTS ON THE POTENTIAL SIGNIFICANCE OF NEUROECONOMICS FOR ECONOMIC THEORY
}

\author{
RaN SpIEgler
}

University College, London

In this short note I speculate about the various ways in which the study of neurological aspects of decision making could be fruitful for economic modelling.

In the numerous discussions on neuroeconomics, commentators react not only to the substance of neuroeconomics but also to the hype that surrounds it. The hype reflects a genuine excitement. Neuroscience is a frontier field which is at least as interesting as economics. Moreover, it has the scientific and high-tech cachet that economists find irresistible. Still, it is a hype and as such it tends to trigger critical responses.

I agree with many of the criticisms. Like Harrison (2008), I am taken aback by the small samples that characterize neuroeconomics studies, the methodology of pooling subjects, and the heavy statistical machinery required to make raw fMRI data amenable to analysis. Like Rubinstein (2006), I observe that so far, neuroeconomics has consisted of attempts to find neural correlates to existing behavioural concepts (for instance, Sanfey et al. (2003) correlate subjects' reaction to insolently low offers in the Ultimatum Game with activity in a brain area which researchers have learned to associate with a sense of disgust), and as such may be great news for neuroscience but is hardly newsworthy for economics.

And like Gul and Pesendorfer (2005), I am not convinced that the mere fact that decision making takes place in the brain implies that neuroscience is necessarily relevant for economic analysis. For example, Roth (2006) emphasizes the role of repugnance in limiting market transactions. Clearly, repugnance has its brain-level correlate. But as Roth points out, the 
classification of market transactions as repugnant has changed a lot in history and across cultures. Thus, the brain level is perhaps not the interesting one when it comes to understanding the determinants of repugnance in economic contexts. A historical and anthropological research perspective seems more suitable.

However, in this short note I do not wish to engage in criticisms of neuroeconomics or the hype surrounding it. Instead, I will try to "think positive" and speculate about some ways in which research in neuroeconomics might contribute to economic theory. There are other ways in which neuroeconomics may prove influential. For example, Benhabib and Bisin (2008) suggest that neuroeconomics can change the way economists confront decision models with data, by viewing decision models not only as theories of choice behaviour but also as theories of the decision process. Benhabib and Bisin propose an empirical methodology that tests decision models against joint choice and brain-level data.

In what follows, I restrict attention to pure economic theory, assuming that the tradition of economic modelling as a primary activity for economists will continue unabated, and I wonder how neuroeconomics might contribute to this activity. This speculative exploration of the possibilities of neuroeconomics for economic theory borders on science fiction. One could also argue that speculating about future models is idle. If one thinks a certain model might be interesting, then one should try actually constructing one rather than speculating about it. Nevertheless, this kind of speculation is in its way a kind of constructive criticism. I have spent some time thinking about how neuroeconomics could contribute to economic modelling, and this is what I have been able to come up with. If the reader does not find this exciting, then this will have suggested that the case for the relevance of neuroscience for economic theory is not a trivial one to make.

\section{Correlations between personality traits}

Economic theory compartmentalizes personal characteristics according to the domains of choice behaviour to which they pertain. Risk attitudes are defined in terms of preferences over lotteries, patience in terms of preferences over dated prizes, social preferences in terms of choices between asset allocations, etc. As neuroeconomists gather non-choice data in experiments, they may stumble upon correlations between personal characteristics that are independent a priori. For example, risk aversion may be correlated with social preferences, patience may be correlated with $\mathrm{IQ}$, and so forth.

In principle, one can discover such correlations without looking at non-choice data, since these personal characteristics are defined purely in terms of choice behaviour. However, when looking at the non-choice 
data that accompany risk aversion or social preferences, the researcher may be struck by similar patterns, and this may give the researcher the motivation to look for correlations in the corresponding choice data. Thus, although neuroscience is not necessary for discovering such correlations, doing neuroeconomic research may be a good heuristic for stumbling upon them.

The implication of such correlations for economic theory is that we can impose them as a constraint on models that incorporate several personal characteristics. In particular, such restrictions on the domain of personal characteristics may be relevant for mechanism design problems. There is also a possibility that economists will be led to doubt the existing compartmentalization of personal characteristics into risk attitudes, social preferences, time preferences, etc. For example, if patience is highly correlated with IQ and risk attitudes are highly correlated with social preferences, then perhaps our current categories miss something essential about decision making. This is an admittedly far-fetched thought. Given that so far neuroeconomics has mostly consisted of looking for neural correlates of existing economic concepts, it is hard to see how such a radical prospect could ever materialize. Speculating about it, however, is easy.

\section{Motivating process-based models of decision making}

The standard economic approach to modelling decision making is based on utility maximization. It does not exclude aspects of psychology such as ambiguity aversion, altruism or self-control problems. However, a standard model always ends up representing choice behaviour with some kind of utility maximization. Thus, the implied decision process is invariably a cost-benefit analysis. Gul and Pesendorfer (2005) argue that the implied decision process is only a metaphor, a rhetorical device. The utility-maximization model is not meant to serve as a "model of the brain". Still, why should we restrict ourselves to the cost-benefit metaphor? As Salant and Rubinstein (2007) argue, there is no reason why we cannot conduct similar decision-theoretic exercises, in which observable behaviour (in a general sense that includes sensitivity of choice to framing, as well as non-choice behaviour such as the time it takes agents to reach a decision) is shown to be the possible result of some decision process other than a cost-benefit analysis.

And yet, after so many years of applying the cost-benefit metaphor, how resourceful can we expect economists to be at inventing original ones? This is where neuroeconomics can prove useful as a heuristic for hitting on good ideas about the decision process, precisely because neuroeconomics is mostly preoccupied with physiological mechanisms behind decision making. 
To illustrate my point, consider an important aspect of decision making which has nevertheless been virtually neglected by economists. Indecisiveness seems to be a personal trait that characterizes an individual at least as well as his time preferences. Reaching decisions is easy for some people, a torment for others. We can try to define indecision purely in terms of observed choice correspondences, as in Eliaz and Ok (2006). We could also try to define it in terms of other choice behaviour, such as the amount of irrelevant information the decision maker seeks before making a decision, or the extent to which he prefers default options, or the extent to which the framing of decision problems refines his choice correspondence. We could also try to define indecision in terms of observable non-choice behaviour, such as the time it takes for the individual to make a decision, or the amount of flip-flopping and head scratching he goes through before he reaches the final decision.

Still, if the end point of our decision-theoretic analysis is going to be a utility-maximization representation theorem (capturing some tradeoff between material payoffs and the mental cost of thinking about the decision), then we have restricted ourselves to a very thin reservoir of metaphors. Is cost-benefit analysis the most convincing metaphor for indecision? By thinking hard about the mechanisms behind the decision process, we can try to conceptualize indecision as a "bottleneck" in a linear processing mechanism, or as a "stalemate" between several parallel processes, which may be more convincing metaphors for indecision.

\section{Legitimizing other non-choice data}

One of the main claims of neuroeconomists is that non-choice data are relevant for economic analysis. While this claim is often employed to justify gathering expensive fMRI data, it also justifies looking at additional, cheaper non-choice data such as response times, look-ups, etc. For psychologists, these types of data may be old hat, but for economists the idea that looking at these things might be interesting is quite new. Ironically, the high-tech cachet of neuroscience has the side benefit of drawing economists' attention to lower-tech non-choice data. Economic theorists, who are accustomed to the exercise of mapping properties of choice behaviour to mental constructs such as utility or beliefs, can extend their techniques to this richer set of non-choice data.

\section{Modelling the implications of neuroscience-driven technological innovations}

Major technological innovations inspire new classes of models, even if they do not cause changes in fundamental economic concepts. For 
example, the internet has given rise to new classes of models of two-sided markets, position auctions and keyword-based search (see Ellison and Fisher-Ellison 2005; Athey and Ellison 2007; Eliaz and Spiegler 2007), where modelling assumptions gain their motivation and focus from real-life features of internet technology. The impact of new technology on economic thinking can be purely metaphorical. For instance, the E-mail Game (Rubinstein 1989) would be perfectly interpretable even if e-mail technology never existed, but the technology may have provided the inspiration and probably helped attracting attention to the paper.

Advances in neuroscience may have similar impact. Imagine that some day, scientists discover some rough mapping between a set of chemicals and a set of personality traits (risk attitudes, time preferences, social preferences, optimism, truthfulness, indecisiveness, etc.). Suppose further that these chemicals become pervasive tradable commodities. This may inspire an interesting class of economic market models, because certain traits which are currently assumed to be immutable will now be an outcome of agents' choices in the market for character-modifying chemicals.

At some level, we already have some experience with such models. There is a sizeable economic literature on the demand for addictive substances (Becker and Murphy 1988; Bernheim and Rangel 2004; Gul and Pesendorfer 2007). This literature treats the consumption of addictive substances as a specialized topic, without integrating it into larger economic models. However, character-modifying chemicals may become so pervasive and related to other aspects of economic behaviour that economists will be impelled to develop entirely new classes of market models, even if these will not call for new basic modelling tools.

None of the above seems to necessitate neuroscientific knowledge, but such knowledge can certainly inspire new economic assumptions and models. The reader may have observed that I have emphasized the role of advances in neuroeconomics as a potential source of inspiration for economic theorists, thus perhaps underplaying its promise to yield empirical foundations for economic models. I would like to conclude with a comment on this distinction.

Two of the biggest success stories in behavioural economics so far are Prospect theory and hyperbolic discounting. Even in these successful models, there is a substantial gap between the assumptions solidly based on experimental psychology and the way the models are actually applied. In order to apply Prospect theory, one needs to specify what determines the reference point. It is a crucial component of any application of the model, and yet it is hard to justify any particular specification with empirical 
psychological knowledge. One has no choice but to complement the model with assumptions based on introspection and anecdotal evidence. Similarly, since time preferences with hyperbolic discounting imply dynamically inconsistent preferences, economists use the multi-selves approach when applying hyperbolic discounting. As Rubinstein (2006) remarks, in order to "solve" the resulting intra-personal game, economists resort to some game-theoretic solution concept (backward induction with sophisticated or naive beliefs about future preferences). The justification of this modelling procedure is not based on empirical evidence, but on other criteria that economists find persuasive.

In both cases, there is a substantial gap between the empirically founded assumptions and the assumptions one needs to make the model tick. The most one can claim is that empirical knowledge has motivated some of the crucial assumptions. I do not expect neuroeconomics to change this practice. But my preference to view neuroeconomics as a source of inspiration is not meant to belittle the field. On the contrary; inspiration is a scarce resource, and if neuroeconomics ends up being successful in giving economic theorists the motivation, focus and minimal empirical knowledge they need to come up with new, interesting and insightful models, that will be a wonderful achievement.

\section{REFERENCES}

Athey, S. and G. Ellison. 2007. Position auctions with consumer search. Mimeo. Cambridge, MA: MIT, Press.

Becker, G. and K. Murphy. 1988. A theory of rational addiction. Journal of Political Economy 96: 675-700.

Benhabib, J. and A. Bisin. 2008. Choice and process: theory ahead of measurement. In Perspectives on the future of economics: Positive and normative foundations. Handbook of economic methodology, Vol. 1, ed. A. Caplin and A. Schotter. New York: Oxford University Press.

Bernheim, D. and A. Rangel. 2004. Addiction and cue-triggered decision processes. American Economic Review 94: 1558-90.

Eliaz, K. and E. Ok. 2006. Indifference or indecisiveness? Choice theoretic foundations of incomplete preferences. Games and Economic Behavior 56: 61-86.

Eliaz, K. and R. Spiegler. 2007. Consideration sets and competition marketing. Mimeo. London: UCL and Brown University.

Ellison, G. and S. Fisher-Ellison. 2005. Lessons about markets from the internet. Journal of Economic Perspectives 19: 139-58.

Gul, F. and W. Pesendorfer. 2005. The case for mindless economics. In Perspectives on the future of economics: Positive and normative foundations. Handbook of economic methodology, Vol. 1, ed. A. Caplin and A. Schotter. New York: Oxford University Press.

Gul, F. and W. Pesendorfer. 2007. Harmful addiction. Review of Economic Studies 74: $147-72$.

Harrison, G. 2008. Neuroeconomics: a critical reconsideration. Economics and Philosophy 24.

Roth, A. 2006. Repugnance as a constraint on markets. Journal of Economic Perspectives 21: $37-58$. 
Rubinstein, A. 1989. The Electronic Mail Game: A Game with Almost Common Knowledge. American Economic Review 79: 385-91.

Rubinstein, A. 2006. Comments on behavioral economics. In Advances in economic theory (2005 World Congress of the Econometric Society), Vol. II, ed. R. Blundell, W. K. Newey and T. Persson, 246-54. New York: Cambridge University Press.

Salant, Y. and A. Rubinstein. 2007. Some thoughts on the principle of revealed preferences. In Perspectives on the future of economics: Positive and normative foundations. Handbook of economic methodology, Vol. 1, ed. A. Caplin and A. Schotter. New York: Oxford University Press.

Sanfey, A., J. Rilling, J. Aronson, L. Nystrom and J. Cohen. 2003. The neural basis of economic decision-making in the ultimatum game. Science 300: 1755-8. 